\title{
Application of Multimodal Learning in Online English Teaching
}

http://dx.doi.org/10.3991/ijet.v10i4.4697

\author{
Meiwei Sun \\ Heze University, Heze, China
}

\begin{abstract}
Mode means the method of using human sensory organs in the external environment; the interaction with only one sensory organ is called single mode and the simultaneous interaction with more than one sensory organ is called multi-mode. A multimodal online English teaching system was designed and applied in online teaching of English in the architecture major. The students were divided into an experimental group and control group. Conventional teaching was adopted for the control group, while multimodal online systematic English learning was adopted for the experimental group. According to employment statistics, it was shown that the experimental group presented some advantages in employment, relieving employment pressure. Multi-mode learning has a good application effect in English teaching in science and engineering, suggesting that the multimodal online teaching system design can be applied to online English teaching.
\end{abstract}

Index Terms - online teaching system, multimode, English

\section{INTRODUCTION}

In recent years, rejuvenation of the state through science and education has become a road of development greatly supported by the government, and technology, economic and cultural exchanges between countries have become more and more frequent [1]. More and more foreign-funded enterprises have settled in China, while many enterprises in China also have changed into Sino-foreign joint ventures for development. These changes require students of science and engineering to not only own solid professional knowledge but also to master at least one foreign language. As a language commonly used worldwide, English has become the first choice of university students. Learning English can improve the oral expression ability and interpersonal communication ability of science and engineering students and improve their competitiveness. It also brings them more opportunities.

At present, there are still some shortcomings in teaching English for science and engineering: (1) Limited by their own experience, some teachers are incapable of combining English with the professional knowledge of science and engineering, which often causes a divorce between theoretical research and actual application [2]. (2) Some English teachers do not have enough ability to impart the knowledge and skills to others [3]. (3) Examinationoriented education has been rooted in people's minds for years, making the students learn with an attitude of no failure allowed on examinations, and such a learning attitude is inevitably difficult to obtain. (4) There is only an emphasis on the language system and semantic structure themselves and their relation with the social culture and psychological cognition, while other meaningful expression forms such as image, sound, color and animation are ignored, which greatly limits the discourse analysis. The multimodal discourse analysis emerging in the Western countries in the 1990s can help people overcome these limitations to a great extent.

Mode means the method of using human sensory organs in the external environment; the interaction with only one sensory organ is called single mode and the simultaneous interaction with more sensory organs is called multi-mode. Some scholars have made corresponding explorations. Royce [4] researched the complementarity of different symbols in multimodal discourse and the synergy of using multiple modes in second language class teaching. Chen Lang designed a multimodal website of Public English Speech [5] and applied some technologies in English teaching. The multimodal teaching method is a teaching method proposed to correspond to the theory of "diversified literacy ability cultivation," which was proposed by Stein in 2000. Stein thought that each type of communication and interaction in class is multimodal and that the teaching and comments should be centered on the multimodal characteristics of the environment [6]. Martinec (2005) proposed a framework for researching multimodal discourse formed by image and language. In this frame, the communication mode of language and image are divided into four layers: ideology, genre, register, and discourse meaning [7]. Martinec thought that linguists should be more concerned about the relationship of multimodal discourse and multiple communication mode synthesis (like language, dynamic images and static images, plus 3D objects) in meaning expression and understanding.

In order to improve the dilemma of science and engineering students in English learning, a new learning mechanism is proposed in this paper, i.e., using multimodal online teaching to replace traditional teaching and to change the students' learning style to achieve the purpose of improving their English.

\section{SYSTEM DESIGN AND REALIZATION OF MULTIMODAL LEARNING}

Under the background of the rapid development of science and technology, human beings have entered an information age in which they can share information and exchange language through the internet and other scientific and technological products. Multimodal teaching is generated under such a background. Traditional teaching is represented as the teachers teaching, students learning, and respective responsibility, but unlike the traditional teaching method, multimodal online teaching stresses greater interaction between teachers and students. Under 
this mode, the teachers use a multimodal method for online teaching, while the students use it for learning, and the teachers and students even can exchange roles occasionally to reach better teaching effects [8]. This mode fully mobilizes the interaction between various modes through interaction transformation among the teachers, the internet and students to construct the students' knowledge, reflect the students' subject knowledge, and finally achieve a diversified literacy ability [9].

In the online teaching multimodal model, teachers should often help the students experience a real language environment, according to the students' actual conditions through a combination of the internet, multimedia options, and other means [10] and through sensory stimulations like hearing and vision to improve the students' ability to use the language. Based on this principle, an interactive learning system was designed. In order to improve the students' incentive, the content included in the system is closely related to the students' lives and involves in a lot of job application interviews and content relevant to architecture. Figure 1 is the interaction diagram of the system structure.

This system consists of three components, including teaching resources, teachers, and students. Each student and teacher logging into this system can acquire the teaching resources, and students also can interact with the teachers. Of course, interaction between teachers and teachers and students and students is also available.
This multimodal learning system consists of 6 parts: Basic Tasks, Watch a Sitcom, Become a Movie Star, I Have a Question, Share Something, and One Day, One Topic. The system composition is as shown in Figure 2.

In Basic Tasks, students are required to learn the words and sentence patterns featured every day, which are aimed at increasing their vocabulary and to correct inaccurate grammar. In the Watch a Sitcom section, the teachers mainly play a sitcom for the students, which consists of two parts. One is watching a sitcom related to job hunting, and some content like English interviews, English résumé production and self-introduction in English are selected. The other is a video related to architecture, which is aimed at improving their listening ability and enriching their major-related vocabulary. In the part of Becoming a Movie Star, there are four voice chat rooms, and the students can freely enter the chat rooms and can be embodied as the film stars to replay the above sitcom. In this way, it is possible to better improve their oral ability. I Have a Question is used for asking questions. The students can ask questions about anything they do not understand. Share Something is a place to share new words and sentence patterns they learn, and even gossip about the news to create a happy learning environment. One Day, One Topic is a written format chat room where a social phenomenon or current news can be selected every day as the topic to combine education with recreation and change the rigid image of traditional teaching. Figure 3 is the system menu diagram.

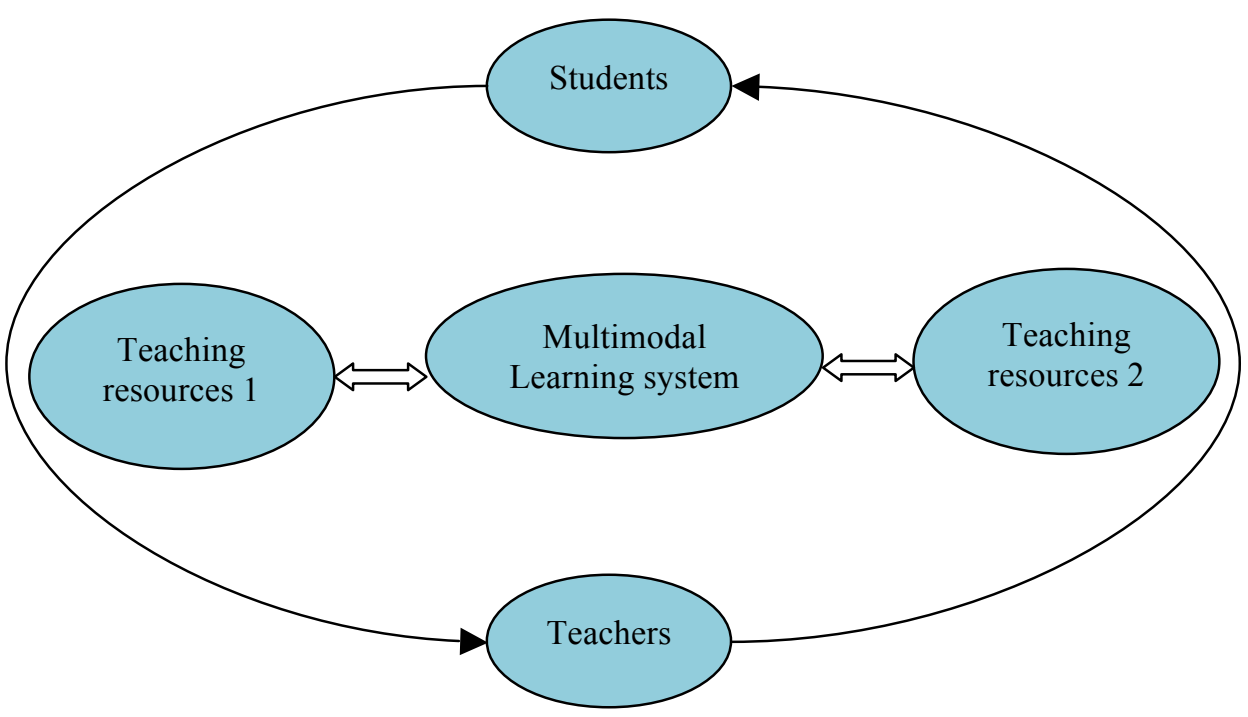

Figure 1. Interaction diagram of system structure

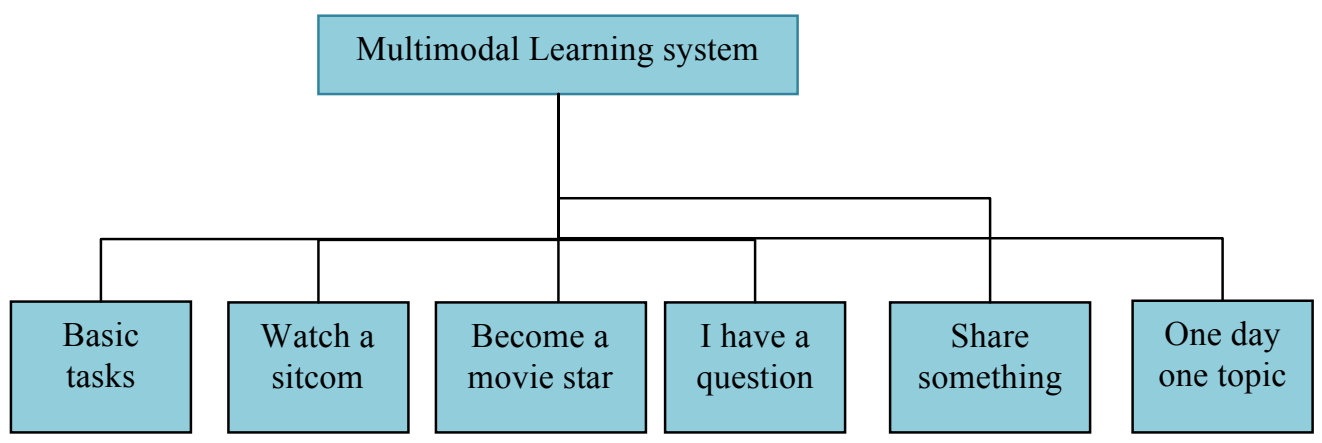

Figure 2. System composition diagram 


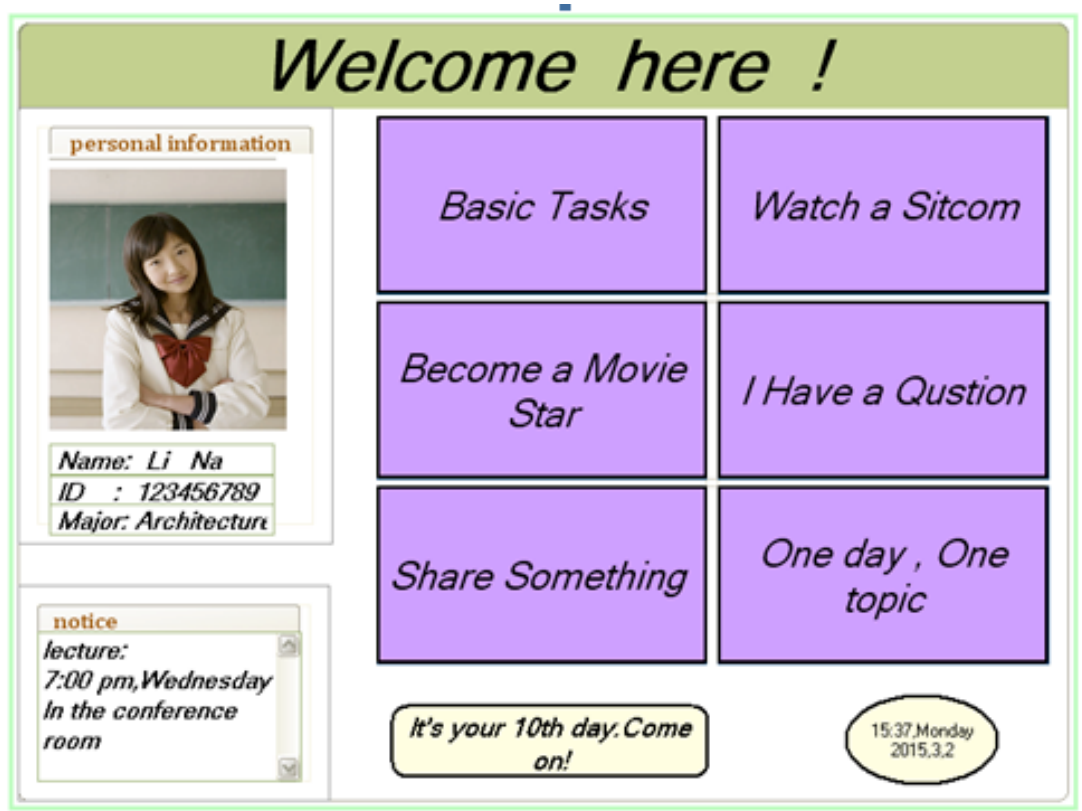

Figure 3. System menu diagram

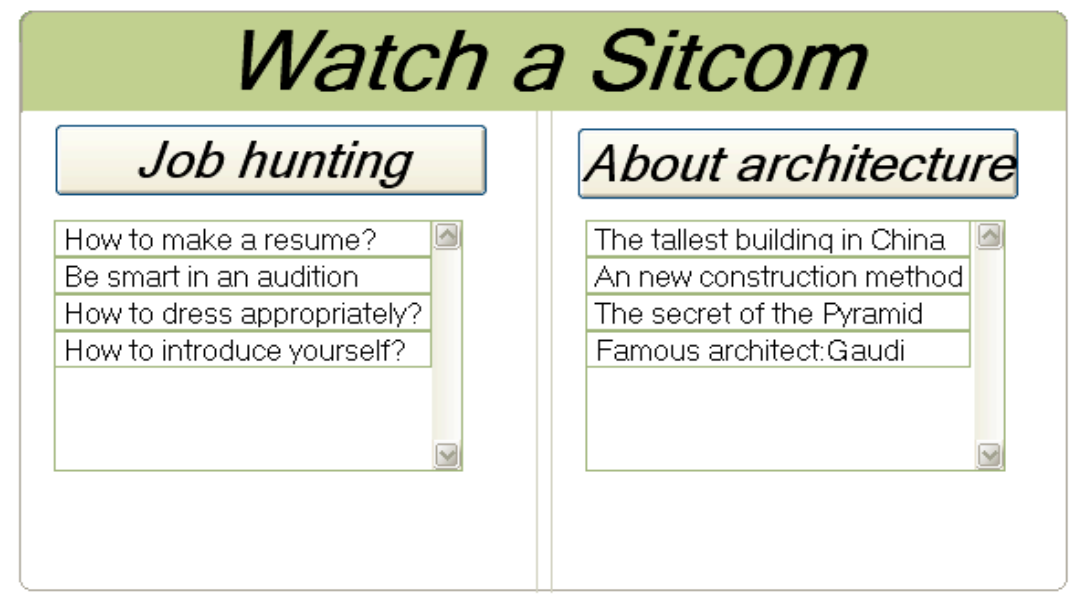

Figure 4. System submenu diagram

The upper left corner of the menu displays the personal information of the person logging in, including name, ID, major and personal photo; the lower left corner is the notice column, which is used to announce lecture information or training information, etc. There is a notice about a lecture shown in the figure. The core part of the menu is 6 functional options that can be clicked to proceed to the lower submenu. There are two labels at the lower right corner: one is the clock and the other is used to display the days the person logged into the system. When the person logs into this system for the first time every day and stays for more than 30 minutes, the counter will add 1, and this record can play serve as supervision and incentive to a certain extent.

Figure 4 is the submenu diagram of Watch a Sitcom. As shown in the figure, this part consists of two blocks. Each block has relevant video content for selection, and everyone can select relevant videos to watch according to interest and demand. In the Job Hunting block, the students enter in advance to understand the state of job hunters to prepare for job hunting; the About Architecture block offers knowledge related to architecture in English learning.

\section{MUlTimode-BASED ONLINE TEACHING EXPERIMENT}

\section{A. Experimental objects}

A lecture on the importance of learning English is selected to be carried in a graduate class of the architecture major in the university. There are 612 graduate students in the architecture major, and each student is notified to participate in the lecture through a short message; 545 students attended the lecture, with an attendance rate of $89 \%$. After the lecture, the students voluntarily attending the learning English lecture were counted, totaling 462, accounting for $84.8 \%$ of the participants.

The 462 students were divided into two groups, respectively the experimental group and control group with 231 in each group. The students in the experimental group and 
control group were tested in English ability - mainly English writing ability, reading ability, listening ability, and oral English ability. The comprehensive English ability of the students was evaluated through tests.

The English ability test was designed to examine the students' comprehensive English ability. The English ability of everyone was classified in the following levels according to the score: 1 . entry level (score $<55)$; 2 . good ( $55 \leq$ score $<70)$; 3 . skillful $(70 \leq$ score $<85$ ), and master $(85 \leq$ score $\leq 100)$, in which entry level represents basic English ability; good represents the use of English skillfully, but with more grammar errors; skillful represents accurate mastery of grammar and sentence pattern under the premise of using English skillfully; master represents that the students can use English as a native language. The results are shown in Table 1 .

In the experimental group, there were 88 students at entry level, with a minimum score of 15 and a maximum score of 55; 92 at the good level, with a minimum score of 56 and a maximum score of $68 ; 37$ at the skillful level, with a minimum score of 72 and a maximum score of 83 , and 14 at the master level, with a minimum score of 85 and a maximum score of 97.

In the control group, there were 80 students at entry level, with a minimum score of 17 and a maximum score of $54 ; 100$ at the good level, with a minimum score of 55 and a maximum score of $69 ; 38$ at the skillful level, with a minimum score of 70 and a maximum score of 82 , and 13 at the mastered level, with a minimum score of 85 and a maximum score of 99 .

The scores of the two groups were input into SPSS V19.0 for statistical analysis, and the mean value and deviation of the two groups of students were respectively calculated, as shown in Table 1:

TABLE I.

ENGLISH TEST RESULT OF EXPERIMENTAL GROUP AND CONTROL GROUP BEFORE EXPERIMENT

\begin{tabular}{lcc}
\hline & Experimental group & Control group \\
\hline Number of students & 231 & 231 \\
Mean value & 67.23 & 66.59 \\
Deviation & 11.69 & 11.33 \\
\hline
\end{tabular}

According to the average value and deviation, it can be said that the English level of the two groups did not have a large difference before the experiment.

By summarizing the scores of the two groups, it can be concluded that the mean value of the overall scores is 66.91, showing that the English score of students in the architecture department is poor overall. The score frequency distribution sheet was made with the number of the participants in various stages as the longitudinal coordinate and the score as the transverse coordinate, as shown in Figure 5:

It can be concluded from the distribution graph that the scores of the students of architecture department are mainly concentrated at the entry level and the good level, respectively accounting for $36.4 \%$ and $41.6 \%$, while the total number of students in the good and skillful states is only 102 , only accounting for $22.1 \%$ of the total number.

\section{B. Experiential methods}

The control group procedures were not changed. The English class was taken as usual, while in the experi-

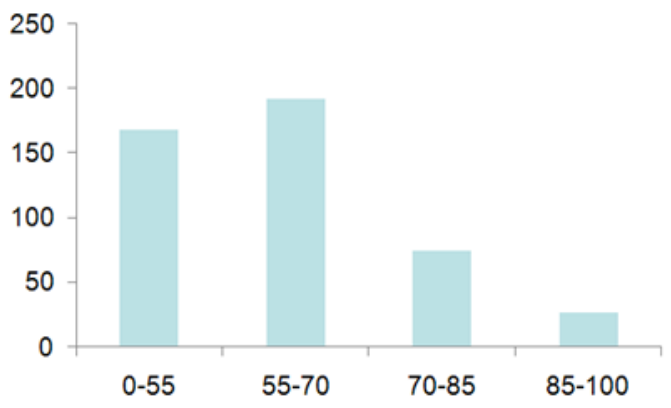

Figure 5. Overall score frequency distribution

mental group, the multimodal learning system was used to learn English. Forty-five days later, the two groups of students were tested in English ability as well as English listening ability and oral English ability.

\section{Experiential results}

The table below shows the comprehensive ability test of experimental group and control group.

TABLE II.

ENGLISH TEST RESULT OF EXPERIMENTAL GROUP AND CONTROL GROUP AFTER EXPERIMENT

\begin{tabular}{lcc}
\hline & Experimental group & Control group \\
\hline Number of students & 231 & 231 \\
Mean value & 75.64 & 68.25 \\
Deviation & 8.75 & 10.27 \\
\hline
\end{tabular}

Upon analysis of these statistical results, it was found that the score of the control group without any course changes is slightly increased, with the average score increasing from 66.59 to 68.25 , only increasing by 1.66 . While in the experimental group, after using the multimodal learning system for 45 days, the score increased significantly; the average score increased from 67.23 to 75.64 , increasing by 8.41 . When comparing the scores of the experimental group and the control group, it was found that the score in the experimental group greatly increased compared to the control group. This change is persuasive, verifying the effectiveness of the multimodal learning system.

Upon segmentation of the scores of the students in the experimental group, it can be concluded that the number of students in entry level is 51, 111 in the good level, 52 in the skillful level and 17 in the master level.

Figure 6 shows the histogram of the score frequency distribution of the experimental group before and after the experiment, in which the transverse coordinate represents the score and the longitudinal coordinate is the number of students corresponding to each score segment.

Through the analysis shown in Figure 6, it was found that before and after the experiment, there was a great change in score for the experimental group, with the number of students with scores ranging from 0 to 55 decreasing from 88 to 57 , reducing by 31 , with a decreasing rate of $72.5 \%$. The number of students with scores ranging from 55 to 70 increased from 92 to 111 , increasing by 19, with an increasing rate of $17.1 \%$. The number of students with scores ranging from 70 to 85 increased from 37 to 52 , increasing by 15 , with an increasing rate of $40.5 \%$. The number of students with scores ranging from 85 to 100 increased from 14 to 17 , increasing by 3 , with an increasing rate of $21.4 \%$. 


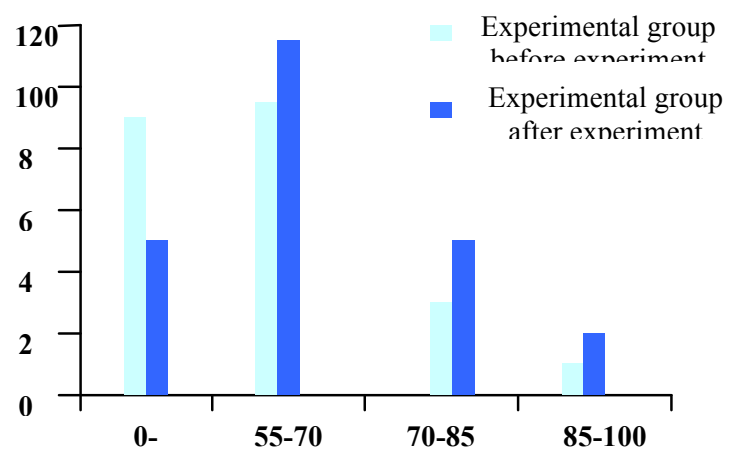

Figure 6. Score frequency distribution of the experimental group before and after experiment

After the experiment, a questionnaire investigation was conducted with participants from the experimental group, and this investigation mainly examined whether the experimental participants increased their interest in learning and whether they improved their confidence in learning English after using the multimodal learning system; 78\% of the interviewees expressed that this system changed the stiff mode of conventional English teaching, making people "fresh" and stating that it has rich content closer to practical application. Therefore, they changed their resistance to learning English and expressed that they were willing to further use this system. Of the interviewees, $66 \%$ expressed that after a period of learning, they felt their English had improved significantly and that to a certain extent they increased their confidence in learning English.

To understand whether the students' English level helped the students in the architecture department in their job hunting, the job hunting condition of the participants in the experimental group and the control group was traced and the results were counted. By June 25, 196 stu- dents in the control group had signed agreements, with a signing rate of $85 \%$; a total of 215 students in the experimental group had signed agreements, with a signing rate of $93 \%$. Based on the signing rate, group 2 was superior to group 1.

The nature of the units in which the participants of the two groups signed agreements are classified, respectively, as foreign-funded enterprise, Sino-foreign joint venture, state-owned enterprise, private enterprise and others. The statistical results are shown in Table III.

Upon comparison of results of the two groups, it was found that more students in the control group signed agreements with foreign-funded enterprises and Sinoforeign joint ventures; the proportion was higher. Facing great employment pressure, with the advantage in English, selecting to join foreign-funded enterprises or Sino-joint ventures no doubt greatly relieved the employment pressure and created more employment opportunities. Furthermore, in recent years, the foreign enterprises and Sinoforeign joint ventures have given better and better treatment, so mastering a foreign language can bring more considerable salary treatment.

\section{CONCLUSION}

A multimodal English learning system was designed, and through demonstration of online teaching in an architecture class it was found that the multimodal learning system was of great help in improving the students' English learning ability and had a significant effect on the students with scores in the middle or lower levels. At the same time, this system also increased the students' English learning interest and enhanced their self-confidence to learn English well. This experiment has fully proved the efficiency of multimodal online learning systems and is expected to be promoted throughout the whole university.

TABLE III.

STATISTICS OF AGREEMENT SIGNING

\begin{tabular}{|c|c|c|c|c|c|}
\hline & Foreign-funded enterprise & Sino-foreign joint venture & State-owned enterprise & Private enterprise & Others \\
\hline Group 1 & 18 & 34 & 14 & 105 & 25 \\
\hline Group 2 & 32 & 52 & 12 & 97 & 22 \\
\hline
\end{tabular}

\section{REFERENCES}

[1] Robert C.K., "Language teachers: Research and studies in language(s) education, teaching, and learning in Teaching and Teacher Education, 1985-2012," Teaching and Teacher Education, vol. 29, no. 1, pp. 86-96, January 2013.

[2] Zhuang Z.X., Huang W., Wang L., "Current Status and Prospect of Multimedia Foreign Language Teaching in China," Media in Foreign Language Instruction, vol. 113, no. 2, pp. 20-27, February 2007.

[3] Huang W.H., He X.Y., "Reasons for English Learning Difficulty of Engineering University Students in Ordinary Universities and their Countermeasures," Journal of Hunan Institute of Engineering (Social Science Edition), vol. 19, no. 3, pp. 97-100, March 2009.

[4] Royce T., "Multimodality in the TESOL classroom: Exploring Visual-verbal Synergy," TESOL QUARTERLY, vol. 36, no. 2, pp. 191-205, February 2002. http://dx.doi.org/10.2307/3588330

[5] Chen L., Zhang J.Y., "Website Design and Teaching Model Innovation of Multimodal Public English Speech," Media in Foreign Language Instruction, no. 154, pp. 50-55, November 2013.

[6] Stein P., "Rethinking Resources Multimodal Pedagogies in the ESL Classroom," TESOL QUARTERLY, vol. 34, no. 2, pp. 333336, January 2000. http://dx.doi.org/10.2307/3587958
[7] Martinec R. and Salway A., "A System for Image- Text Relations in New (and Old) Media," Visual Communication, vol. 4, no. 3, pp. 337-371, June 2005. http://dx.doi.org/10.1177/1470357205055928

[8] Yang M., Li Q.M., Song Y.L., "A SEIR Model Epidemic of Virus on the Online Social Network," Journal of Digital Information Management, vol. 12, no. 2, pp. 102-107, April 2014.

[9] Mills K.A., "Shrek Meets Vygotsky: Rethinking Adolescents' Multimodal Literacy Practices in Schools," Journal of Adolescent \& Adult Literacy, vol. 54, no 1, pp. 35-45, September 2010. http://dx.doi.org/10.1598/JAAL.54.1.4

[10] Tsou W.L., Wang W.C., Tzeng Y.J., "Applying a multimedia storytelling website in foreign language learning," Computers \& Education, vol. 47, no. 1, pp. 17-28, August 2006. http://dx.doi.org/10.1016/j.compedu.2004.08.013

\section{AUTHOR}

Meiwei Sun is a lecturer in the Department of Foreign Languages, Heze University, Heze, 274015, China. Her research interests include multimodal learning and online education (sunmeiwei12@yeah.net)

Submitted 05 May 2015. Published as resubmitted by the author 20 August 2015. 